\title{
The epidemiology and pathophysiology of pseudobulbar affect and its association with neurodegeneration
}

This article was published in the following Dove Press journal:

Degenerative Neurological and Neuromuscular Disease

27 May 2013

Number of times this article has been viewed

\section{Rebecca R King \\ Jeffrey P Reiss}

Department of Psychiatry, University of Western Ontario, London Health Sciences Centre, Victoria Hospital, London, Ontario, Canada
Correspondence: JP Reiss Department of Psychiatry, University of Western Ontario, London Health Sciences Centre, Victoria Hospital, 800 Commissioners Road East, London, Ontario N6A 5W9, Canada, Tel +I 5 I 96858500 ext 75665 Fax + I 5196676564 Email Jeffrey.Reiss@Ihsc.on.ca

\begin{abstract}
Pseudobulbar affect is a disorder resulting from neurologic damage manifesting as sudden, stereotyped affective outbursts that are not reflective of internal emotion. A literature review was completed to examine the current understanding of the epidemiology, characterization, diagnosis, pathophysiology, and treatment of pseudobulbar affect. This review revealed that it is common in neurodegenerative disorders but is poorly recognized, placing significant impacts on patients and their families. The disorder appears to result from a disruption of the cortico-limbicsubcortical-thalamic-pontocerebellar network involved in emotional expression and regulation with resulting disruptions of neurotransmitter systems. Effective treatment is available with agents such as selective serotonin reuptake inhibitors and dextromethorphan combined with quinidine, but further well-designed comparative studies are needed. Advances in technology such as neuroimaging may enhance knowledge about the pathophysiology of this disorder, and help guide future interventions.
\end{abstract}

Keywords: pseudobulbar affect, pathological laughing and crying, neurodegenerative disease, pathophysiology, epidemiology, treatment

\section{Introduction}

Pseudobulbar affect (PBA) is a disorder seen in a wide variety of neurologic illnesses, but is particularly common in neurodegenerative diseases such as amyotrophic lateral sclerosis (ALS), Parkinson's disease (PD), multiple sclerosis (MS), and various dementias. ${ }^{1,2}$ It is characterized by stereotyped, involuntary outbursts of affect or objective emotional expressions (such as crying or laughing) that are excessive or incongruent with the individual's subjective emotional experience or mood. ${ }^{1-10}$ In essence, neurologic damage leads to an uncoupling of the subjective experience of emotion or mood from the objective behaviors of emotion or affect that involve motor and autonomic responses. ${ }^{1,11}$ Given that the objective expression of emotion normally reflects the subjective experience of emotion, given that clinicians are generally unaware of PBA as an entity, and given that the disorder is frequent in individuals with severe neurodegenerative disorders with multiple other comorbidities, it is not surprising that PBA is thought to be under diagnosed or misdiagnosed. ${ }^{12-14}$ Varied nomenclature creates additional confusion. The multiple names denoting PBA or related diagnoses are listed in Table $1 .{ }^{2,5,10}$ To further characterize the epidemiology, pathophysiology, diagnosis, and treatment of PBA, a comprehensive literature review of pediatric and adult publications was completed. 
Table I Alternative names for pseudobulbar affect

Pseudobulbar laughing or crying

Pathologic weeping or crying or laughing

Pathologic emotionalism or emotionality

Pathological affect

Organic emotionalism

Involuntary emotional expression disorder

Inappropriate hilarity

Forced laughter or crying

Excessive emotionality

Emotionalism

Emotional lability

Emotional instability

Emotional incontinence

Emotional dysregulation

Emotional dyscontrol

Compulsive laughing or crying

Affective lability

Affective instability

Affective incontinence

\section{Epidemiology}

The occurrence of PBA has been reported in a multitude of neurologic illnesses including, but not limited to, ALS, ${ }^{15-19}$ PD and other movement disorders, ${ }^{13,20-22} \mathrm{MS},{ }^{23-37}$ stroke, ${ }^{38-54}$ various types of dementia and other neurodegenerative disorders, ${ }^{55-62}$ traumatic brain injury (TBI), ${ }^{63-66}$ central nervous system tumors, ${ }^{67-81}$ neurogenetic syndromes,${ }^{82-94}$ and viral cerebellitis. ${ }^{95}$ Rarely, certain therapeutic interventions have also reported PBA as a side effect of treatment. Case reports exist of pathologic laughing as a side effect of paroxetine, ${ }^{96}$ sumatriptan, ${ }^{97}$ and ziprasidone, ${ }^{20}$ as well as deep brain stimulation, particularly of the subthalamic nucleus. ${ }^{98-102}$ However, as will be discussed in this review, some consider medication side effects as an exclusionary criteria for PBA given their usual reversibility and lack of structural neurologic damage. ${ }^{1}$

The reported prevalence of PBA varies greatly depending on the underlying neurologic illness, the methodology of the study, and the diagnostic criteria used to identify cases. A recent online, stratified survey of a nationally representative sample attempted to establish the prevalence of PBA in the United States and specifically the prevalence of PBA in Alzheimer's dementia, ALS, MS, PD, stroke, and TBI. ${ }^{14}$ The estimated prevalence in the US population varied depending on the scale and threshold score used to identify cases, but ranged from a low estimate of 0.55 million to a high estimate of 7.1 million. In the six neurologic conditions surveyed, overall prevalence was $10 \%$ to $38 \%$ depending on the threshold score used. Limitations of the study included a low response rate, use of scales not validated for some of the identified populations, and reliance on respondents to report their neurologic diagnoses accurately. Estimates of prevalence for specific diseases from this study and other studies indicate that true prevalence in neurodegenerative disorders may range from $2 \%-60 \%$ in ALS, $, 2,7,10,145 \%-17 \%$ in PD,,$^{5,13,14} 7 \%-29 \%$ in MS, ${ }^{2,7,10,14}$ and $10 \%-74 \%$ in Alzheimer's dementia. ${ }^{2,5,10,14}$ The prevalence in nondegenerative disorders also shows a broad range of $6 \%-52 \%$ in stroke, ${ }^{2,7,10,14}$ and $5 \%-11 \%$ in TBI. ${ }^{2,5,7,10,14,66}$

Comorbidity is often seen in those with PBA. It is associated with cognitive impairment in $\mathrm{MS},{ }^{103}$ and depression in PD and other movement disorders. ${ }^{13,21}$ There is also an association with anxiety. ${ }^{2,66}$ Aside from structural neurologic disease, there are no consistently associated risk factors for PBA, although an isolated study indicates that premorbid, illicit drug use predisposes to $\mathrm{PBA} .{ }^{66}$ The valence of affective outbursts may be different depending on the laterality of lesions and gender. ${ }^{104}$ Pathologic crying may be more prevalent in women and those with left-sided lesions, while pathologic laughing may be more prevalent in men and those with right-sided lesions. ${ }^{104}$

Quality of life is significantly affected by PBA with apparent detrimental effects on rehabilitation, occupational functioning, social functioning, and quality of relationships. ${ }^{5,13,105}$ This finding is particularly important for progressive neurologic disorders where quality of life is a primary focus of care. A study of patients with movement disorders showed well-being subscores on the 39-question PD questionnaire were significantly lower for those with PBA. ${ }^{13}$ Additionally, those with PBA were more likely to be taking an antidepressant. ${ }^{13} \mathrm{~A}$ recent survey of patients with various neurologic illnesses showed that those with PBA scored significantly lower on the work productivity and impairment questionnaire, quality of life questionnaires, and quality of relationship questionnaires compared with controls, even when disease severity and other confounding factors were controlled. ${ }^{105}$ PBA was the main reason for becoming housebound for $24 \%$ of respondents, and produced significant caregiver burden. ${ }^{105}$ Stigma may also prevent ALS patients with PBA from discussing their symptoms. ${ }^{106}$ Patient and family education is recommended for effective management and to reduce stigma. ${ }^{2}$

\section{Pathophysiology}

The pathophysiology of PBA is likely varied and best conceptualized as a focal or diffuse disruption in the complex neurocircuitry or neurochemistry involved in the inhibition of emotional expression. ${ }^{11,107-115}$ One of the 
original hypotheses about PBA came from Wilson, ${ }^{115}$ who proposed that there was disruption of the cortical inhibition to an upper brainstem center followed by release of lower bulbar nuclei that coordinate the motor responses associated with laughing and crying. Thus, this theory is often called the "release hypothesis." Postmortem and imaging studies in patients with PBA seem to support this theory. ${ }^{11,107,111,113}$ Other support comes from the anatomic location of lesions or activity involved in disorders related to PBA such as "fou rire prodromique," whereby involuntary emotional expression relates to an apoplectic event, ${ }^{3,11,54,79,108,111,116}$ or gelastic or dacrystic seizures where involuntary laughter or crying is part of a seizure. ${ }^{68,71,80,85,117-124}$ More recently, lesions of cerebro-pontocerebellar circuitry have been implicated in PBA. ${ }^{11,107-110}$

At the neurotransmitter level, there is also likely to be dysfunction involved in PBA as evidenced by neuroimaging ${ }^{107,114}$ and based on pharmacologic therapies that will be discussed further, later in this review. Serotonin deficiency, dopamine deficiency, glutamate excess, and sigma type one $(\sigma-1)$ receptor abnormalities have all been implicated. ${ }^{107,113,114}$ Serotonin may be involved in the modulation of emotional expression via ascending serotonergic pathways from the raphe nuclei to the hippocampus, lateral septum and striatum, and frontal cortex. ${ }^{107}$ Further supporting a serotonin deficiency hypothesis, a 2004 single-photon emission computed tomography study of poststroke patients with and without pathological crying showed significantly lower binding ratios of the presynaptic serotonin transporter in the midbrain and pons of those with pathological crying. ${ }^{114}$ The authors theorize a latent vulnerability that is uncovered after neurologic damage. ${ }^{114}$ The effectiveness of serotonergic agents for the treatment of PBA provides support for this hypothesis..$^{10}$ Dopamine functions in the brain to modulate the signal-to-noise ratio of information processing circuits, and too little or too much dopamine disrupts the optimal processing of salient stimuli. ${ }^{107}$ Although there is less evidence to support a dopamine deficiency or excess is a contributor to PBA, it is theorized that nonsalient sensory stimuli trigger automatic motor responses in the form of affective outbursts. ${ }^{107}$ Individual reports of successful treatment of PBA with dopaminergic agents like levodopa support this theory. ${ }^{10}$ Glutamate is the primary excitatory neurotransmitter in the brain, and is proposed to contribute to neurotoxicity in some degenerative disorders such as ALS where PBA is often seen. ${ }^{17}$ Excess excitatory glutamate activity in the specific circuits described above is also theorized to contribute to inappropriate affective outbursts. Modulation, but not complete blockade of N-methyl-D-aspartate (NMDA) receptors through noncompetitive antagonism is thought to reduce the excitatory activity while still allowing for desired activity. ${ }^{10}$ The $\sigma-1$ receptors in the brain are thought to have multiple neuromodulatory functions and possibly an intracellular amplifying or sensitizing role. ${ }^{107}$ Also, $\sigma-1$ receptors are densely distributed in areas theorized to be disrupted in PBA. ${ }^{107}$ The endogenous ligands for these receptors may include gonadal steroids, but some serotonergic and NMDA receptor antagonists also have affinity for these receptors. ${ }^{107}$ This could explain the effectiveness of apparently different pharmacologic agents, but it is unclear; variations in one neurotransmitter often have consequent impacts on the levels of other neurotransmitters.

In summary, as Rabins and Arciniegas ${ }^{107}$ have proposed, PBA is theorized to come from a disruption in a complex cortico-limbic-subcortico-thalamic-pontocerebellar network, which is often related to lesions in descending corticobulbar fibers that inhibit emotional motor networks, lesions in brainstem and cerebellum white matter pathways that modulate emotion expression, and multiple abnormalities in neurotransmitter function.

\section{Characterization and diagnosis}

The varied nosology and lack of consensus about diagnostic criteria has created confusion around the diagnosis of PBA. However, proposed diagnostic criteria are as follows: ${ }^{1}$ paroxysmal episodes of laughing, crying, or other emotional outbursts that are linked to brain damage of some sort and represent a departure from the affected person's affective baseline. Outbursts are sudden, involuntary, uncontrollable, last for seconds or minutes, and are incongruent with or out of proportion to the provoking stimulus, mood or internal state with a quick return to the prevailing mood thereafter. Outbursts are often stereotyped. The outbursts cause distress or dysfunction, and are not accounted for by another disorder or drug effect. Suggestive features include concurrent autonomic changes, pseudobulbar palsy, and episodic anger.

The differential diagnosis of PBA includes certain psychiatric disorders, certain neurologic disorders with mood or affect disturbance, or individuals within the normal spectrum. ${ }^{1,125-127}$ Mood disorders such as depression or bipolar disorder may present with some affective lability, but affect is congruent with mood and episodes last days or weeks not seconds or minutes. Anxiety disorders such as posttraumatic stress disorder or panic disorder can present with episodic 
displays of affect coupled with autonomic reactivity, but the individual will have an internal sense of anxiety. However, as pointed out above, PBA may be comorbid with disorders such as depression or anxiety, and the diagnosis of one does not exclude the other. ${ }^{2,13,21,66}$ Psychotic disorders such as schizophrenia may present with incongruent or odd affect, but the diagnosis is clear based on the other presenting symptoms such as hallucinations, delusions, or disorganized behavior over a period of time. Personality disorders with affective dysregulation such as borderline personality disorder may show sudden and shifting affect, but this is congruent with the internal sense of unstable mood. Alcohol or psychoactive substance intoxication may present with emotional expressions inappropriate to the situation, but this is mood congruent. Witzelsücht is a disorder of mood associated with brain tumors, and more rarely TBI, stroke, or dementia, where patients experience inappropriate situations as genuinely funny or mirthful. Their inappropriate mirth may be mistaken for PBA. Similarly, those with MS may be misdiagnosed with PBA when they experience euphoric moods that appear inappropriate to their circumstance, but mood and affect are congruent. Neurologic disorders of affect may also be mistaken for PBA. As referenced above, seizure activity or aura can present with sudden episodes of laughter or crying in gelastic or dacrystic epilepsy. Risus sardonicus from tetanus infection is a tetanic activation of facial expression resembling laughing, but is unlike PBA otherwise. Finally, essential crying is a normal propensity toward weeping in a small number of individuals, but does not cause impairment. Mood and affect are congruent in essential crying.

Typically, PBA is not the index symptom of a patient's presentation and is accompanied by symptoms and signs suggestive of the underlying neurologic abnormality. ${ }^{125}$ If this is not the case, a complete examination and work-up is indicated considering the diagnostic criteria and differential diagnoses discussed above. This work-up would include a thorough history screening for functional impairment, psychosocial impact, and comorbidities, a physical exam, and indicated investigations based on the likely underlying neurologic disorder.

Multiple scales have been created and validated for screening, diagnostic clarity, research purposes, and monitoring of therapeutic response in PBA. The Center for Neurologic Study-lability scale (CNS-LS) is a self-report measure used to screen for PBA, as a research measure, and to monitor response to treatment. ${ }^{1,12,125-128}$ It has been validated in $\mathrm{ALS}^{12}$ and $\mathrm{MS}^{128}$ with good criterion and construct validity, sensitivity and specificity, test-retest reliability, and internal consistency. The pathological laughter and crying scale (PLACS) is an interviewer-administered questionnaire that can evaluate the severity of symptoms and response to treatment over time. ${ }^{1,125-127,129}$ It has been validated in stroke, ${ }^{129}$ TBI, ${ }^{66}$ and Alzheimer's disease ${ }^{130}$ with good sensitivity and specificity, test-retest reliability, and inter-rater reliability. The PLACS also includes two questions about distress or embarrassment. The emotional lability questionnaire is an adaptation of the PLACS for use specifically in ALS. ${ }^{131,132}$ It has not been validated in other populations but seems to have internal and construct validity for ALS. ${ }^{131,132}$

\section{Treatment}

Although PBA is likely related to specific disruptions of a complex cortico-limbic-subcortico-thalamic-pontocerebellar network, treatments are often targeted more globally. Multiple pharmacotherapies have been effective for the treatment of PBA. ${ }^{133-137}$ The majority of medications are used off-label, with evidence from case reports, case series, small open-label trials, and small randomized, placebo-controlled trials.

Antidepressants have been classically used to reduce the frequency and severity of symptoms. ${ }^{138}$ Within the class of antidepressants, selective serotonin reuptake inhibitors (SSRIs) are some of the most commonly used medications. There are case reports or series, and a small crossover, double-blind, placebo-controlled trial showing the effectiveness of citalopram. ${ }^{139-142}$ Sertraline has been shown to be effective for treatment in a case report and case series, and in double-blind, randomized, placebocontrolled trials. ${ }^{143-145}$ Case series and small open-label trials have supported the effectiveness of fluoxetine, paroxetine, and fluvoxamine. ${ }^{146-151}$ There is also evidence for tricyclic antidepressants treatment of PBA in a small double-blind, placebo-controlled, crossover trial using amitriptyline in MS patients; ${ }^{152}$ a small double-blind, placebo-controlled trial using nortriptyline; ${ }^{129}$ and some evidence for the use of imipramine. ${ }^{153}$ Additionally, there are case reports for the selective noradrenergic reuptake inhibitors venlafaxine, ${ }^{154}$ duloxetine, ${ }^{155}$ and reboxetine. ${ }^{156}$ The action of serotonergic or noradrenergic agents appears independent of antidepressant effect and occurs more quickly than the antidepressant effects of these medications, indicating a distinct mechanism of treatment related to serotonin, or other effects on dopamine or $\sigma-1$ receptors. ${ }^{133-137}$

There is less evidence for the use of other agents such as the mood stabilizer and antiepileptic lamotrigine, ${ }^{157,158}$ 
the atypical antipsychotics quetiapine ${ }^{159}$ and aripiprazole, ${ }^{160}$ and the dopaminergic agents levodopa and amantadine. ${ }^{161,162}$ The theoretical underpinnings of the mechanisms of action are unclear. ${ }^{133-137}$

The only US Food and Drug Administration-approved agent for the treatment of PBA is dextromethorphan/ quinidine (DM/Q) ${ }^{163-167} \mathrm{DM}$ is a noncompetitive antagonist of the NMDA glutamate receptor and was discovered to be effective for PBA while being tested as a treatment to slow the neurotoxicity and progression of ALS. ${ }^{163-167}$ Unfortunately, it was found to be ineffective for slowing the progression of ALS. Of note, DM/Q is also a $\sigma-1$ agonist. ${ }^{163-167}$ The mechanism of action for PBA is not completely clear, but is theorized to be related to the $\sigma-1$ agonist action of DM. These receptors are densely distributed in areas related to emotional expression including limbic and motor regions of the brain as well as the brainstem and cerebellum. ${ }^{166-168} \mathrm{DM}$ is quickly metabolized by cytochrome P450 2D6 isoenzyme, and thus inhibition of this enzyme by $\mathrm{Q}$ is helpful to maintain therapeutic levels of DM for treatment. ${ }^{163-167}$ Two relatively large, randomized, placebo-controlled, double-blind studies of patients with MS and patients with ALS or MS have shown $\mathrm{DM} / \mathrm{Q}$ to be efficacious. ${ }^{163,165}$

Comparatively, the medications above have different benefits and risks of use. For example, SSRIs are relatively well-tolerated and safe, with less impact on the corrected cardiac QT interval, fewer medication interactions than that of $\mathrm{DM} / \mathrm{Q}$, fewer cardiac and anticholinergic side effects than tricyclic antidepressants, and have indications for comorbidities such as depression and anxiety. ${ }^{167,169}$ However, SSRIs have their own risk profile such as an increased risk of bleeding amongst those with ischemic stroke, although mortality does not appear to be impacted. ${ }^{170}$ Overall, DM/Q fared well in safety and tolerability trials. ${ }^{163,164}$ It behooves the clinician to use the relative benefit and side effect profile to help patients and their families make appropriate treatment decisions. ${ }^{167}$

In addition to pharmacologic studies, there is support from small case series for cognitive and behavior therapy for $\mathrm{PBA}^{171,172}$ and an alternative treatment technique called hwangryunhaedogtang, a traditional Chinese medicine approach to address imbalances in the mind and body. ${ }^{173}$

\section{Summary and future directions}

In summary, PBA is a disorder resulting from neurologic damage manifesting as sudden, stereotyped affective outbursts that are not reflective of mood. This condition is common in neurodegenerative disorders. It is poorly recognized, variably characterized, and causes significant distress and dysfunction for patients and their families. Although the biological underpinnings are unclear and likely multiple, there appears to be a disruption of the cortico-limbic-subcortico-thalamic-pontocerebellar network involved in emotional expression and regulation. Neurologic damage likely impacts neurotransmitter systems, and thus pharmacologic treatments are often used to modify neurotransmitters accordingly. Although the exact mechanism of action of pharmacologic treatments is unknown, agents such as SSRIs and DM/Q may be indicated depending on the needs of the individual patient.

The limitations of studies to date include the lack of consensus on diagnostic criteria and terminology, small sample sizes, varied populations presenting with PBA, inconsistent methods used between studies for finding cases, measuring symptoms and response, lack of assessment of comorbidity, lack of long-term data, and lack of comparative studies between the various available pharmacologic agents. ${ }^{1,2,5,7,11}$

It is hoped that identification and treatment of PBA is improved with a consensus on diagnostic criteria allowing for better identification of cases and larger sample sizes for studies. Future studies should identify those with PBA within specific patient populations, particularly amongst neurodegenerative disorders where PBA is more common, to better understand the variations within specific disease processes and guide specific treatments accordingly. Wider validation and use of available screening, diagnostic, and monitoring tools such as the CNS-LS, the PLACS, and the emotional lability questionnaire would provide further case identification, interstudy and intrastudy consistency, comparisons amongst various neurologic diseases, and accurate evaluation of response to treatments. Similarly, assessment of comorbidity using other diagnostic tools for depression, anxiety, cognitive functioning, and psychosocial impact would improve the quality of research in the field. All of the above would be best carried out with a long-term trajectory to monitor patients over the course of their illness. Future neuroimaging studies and advances in technology may further elucidate the exact anatomical, neurotransmitter, and cellular level disruptions in those with PBA. This may also help to inform and refine treatment options. ${ }^{11}$

Outside of pharmacologic interventions, there are multiple future avenues for novel treatments. Cognitive and behavioral therapies, other psychotherapies, and alternative 
medicine treatments have not been well evaluated and warrant further attention based on preliminary studies. ${ }^{171-173}$

\section{Disclosure}

The authors report no conflicts of interest in this work.

\section{References}

1. Cummings JL. Involuntary emotional expression disorder: definition, diagnosis, and measurement scales. CNS Spectr. 2007;12(4 Suppl 5): 11-16.

2. Duda JE. History and prevalence of involuntary emotional expression disorder. CNS Spectr. 2007;12(4 Supp1 5):6-10.

3. Gondim FA, Thomas FP, Oliveira GR, Cruz-Flores S. Fou rire prodromique and history of pathological laughter in the XIXth and XXth centuries. Rev Neurol (Paris). 2004;160(3):277-283.

4. Martin CM. It's nothing to laugh about: understanding disorders of emotional expression. Consult Pharm. 2007;22(9):732-742.

5. Miller A, Pratt H, Schiffer RB. Pseudobulbar affect: the spectrum of clinical presentations, etiologies and treatments. Expert Rev Neurother. 2011;11(7):1077-1088.

6. Husain MM. Emotional lability (pseudobulbar affect) in general psychiatry: an introduction. Am J Geriatr Pharmacother. 2005; 3(Suppl 1):3.

7. Nieuwenhuis-Mark RE, van Hoek A, Vingerhoets A. Understanding excessive crying in neurologic disorders: nature, pathophysiology, assessment, consequences, and treatment. Cogn Behav Neurol. 2008; 21(2):111-123.

8. Presecki P, Mimica N. Involuntary emotional expression disordernew/old disease in psychiatry and neurology. Psychiatr Danub. 2007; 19(3):184-188.

9. Rosen HJ, Cummings J. A real reason for patients with pseudobulbar affect to smile. Ann Neurol. 2007;61(2):92-96.

10. Wortzel HS, Oster TJ, Anderson CA, Arciniegas DB. Pathological laughing and crying: epidemiology, pathophysiology and treatment. CNS Drugs. 2008;22(7):531-545.

11. Parvizi J, Coburn KL, Shillcutt SD, Coffey CE, Lauterbach EC, Mendez MF. Neuroanatomy of pathological laughing and crying: a report of the American Neuropsychiatric Association Committee on Research. J Neuropsychiatry Clin Neurosci. 2009;21(1):75-87.

12. Moore SR, Gresham LS, Bromberg MB, Kasarkis EJ, Smith RA. A self report measure of affective lability. J Neurol Neurosurg Psychiatry. 1997;63(1):89-93.

13. Strowd RE, Cartwright MS, Okun MS, Haq I, Siddiqui MS. Pseudobulbar affect: prevalence and quality of life impact in movement disorders. J Neurol. 2010;257(8):1382-1387.

14. Work SS, Colamonico JA, Bradley WG, Kaye RE. Pseudobulbar affect: an under-recognized and under-treated neurological disorder. Adv Ther. 2011;28(7):586-601.

15. Corcia P, Meininger V. Management of amyotrophic lateral sclerosis. Drugs. 2008;68(8):1037-1048.

16. Gallagher JP. Pathologic laughter and crying in ALS: a search for their origin. Acta Neurol Scand. 1989;80(2):114-117.

17. Mitchell JD, Borasio GD. Amyotrophic lateral sclerosis. Lancet. 2007;369(9578):2031-2041.

18. Olney NT, Goodkind MS, Lomen-Hoerth C, et al. Behaviour, physiology and experience of pathological laughing and crying in amyotrophic lateral sclerosis. Brain. 2011;134(Pt 12):3458-3469.

19. Stromberg SF, Weiss DB. Depression and quality of life issues in patients with amyotrophic lateral sclerosis. Curr Treat Options Neurol. 2006;8(5):410-414.

20. Schindehütte J, Trenkwalder C. Treatment of drug-induced psychosis in Parkinson's disease with ziprasidone can induce severe dose-dependent off-periods and pathological laughing. Clin Neurol Neurosurg. 2007; 109(2):188-191.
21. Siddiqui MS, Fernandez $\mathrm{HH}$, Garvan $\mathrm{CW}$, et al. Inappropriate crying and laughing in Parkinson disease and movement disorders. World $J$ Biol Psychiatry. 2009;10(3):234-240.

22. Cavanna AE, Ali F, Leckman JF, Robertson MM. Pathological laughter in Gilles de la Tourette syndrome: an unusual phonic tic. Mov Disord. 2010;25(13):2233-2239.

23. Aguirregomozcorta M, Ramió-Torrentò LI, Gich J, Quiles A, Genis D. Paroxysmal dystonia and pathological laughter as a first manifestation of multiple sclerosis. Mult Scler. 2008;14(2):262-265.

24. Benedict RH, Carone DA, Bakshi R. Correlating brain atrophy with cognitive dysfunction, mood disturbances, and personality disorder in multiple sclerosis. J Neuroimaging. 2004;14(Suppl 3): $36 \mathrm{~S}-45 \mathrm{~S}$.

25. Feinstein A. Neuropsychiatric syndromes associated with multiple sclerosis. J Neurol. 2007;254(Suppl 2):1173-1176.

26. Feinstein A, Deluca J, Baune BT, Filippi M, Lassman H. Cognitive and neuropsychiatric disease manifestations in MS. Mult Scler Relat Disord. 2013;2(1):4-12.

27. Haussleiter IS, Brüne M, Juckel G. Psychopathology in multiple sclerosis: diagnosis, prevalence and treatment. Ther Adv Neurol Disord. 2009;2(1):13-29.

28. Hoegerl C, Zboray S. Pathological laughter in a patient with multiple sclerosis. J Am Osteopath Assoc. 2008;108(8):409-411.

29. Kocer B, Oner Y, Batur H, Nazliel B, Cengiz B, Tali T. Pathological laughing as a manifestation in a clinically isolated brainstem syndrome: a case report. J Neuroimaging. 2009;19(3):291-294.

30. Lantz MS. Pathologic laughing and crying in multiple sclerosis. Clin Geriatr. 2005;13(7):14-17.

31. Okuda DT, Chyung AS, Chin CT, Waubant E. Acute pathological laughter. Mov Disord. 2005;20(10):1389-1390.

32. Paparrigopoulos T, Ferentinos P, Kouzoupis A, Koutsis G, Papadimitriou GN. The neuropsychiatry of multiple sclerosis: focus on disorders of mood, affect and behaviour. Int Rev Psychiatry. 2010; 22(1):14-21.

33. José Sá M. Psychological aspects of multiple sclerosis. Clin Neurol Neurosurg. 2008;110(9):868-877.

34. de Seze J, Zephir H, Hautecoeur P, Mackowiak A, Cabaret M, Vermersch P. Pathologic laughing and intractable hiccups can occur early in multiple sclerosis. Neurology. 2006;67(9):1684-1686.

35. Swamy MN, Johri S, Gorthi SP, et al. Pathological laughter, multiple sclerosis, behavioural abnormality. Med J Armed Forces India. 2006; 62(4):383-384.

36. Wilken JA, Sullivan C. Recognizing and treating common psychiatric disorders in multiple sclerosis. Neurologist. 2007;13(6):343-354.

37. Yalug I, Ozdemir S, Kirmizi-Alsan E, Kutlu A, Efendi H, Siva A. Psychiatric aspects of multiple sclerosis. Neurology Psychiatry and Brain Research. 2007;14(2):67-74.

38. Arif H, Mohr JP, Elkind MS. Stimulus-induced pathologic laughter due to basilar artery dissection. Neurology. 2005;64(12):2154-2155.

39. Asfora WT, DeSalles AA, Abe M, Kjellberg RN. Is the syndrome of pathological laughing and crying a manifestation of pseudobulbar palsy? J Neurol Neurosurg Psychiatry. 1989;52(4):523-525.

40. Awada A, Halaby G, Tamraz J. Spasmodic laughter syncope. An unusual complication of pseudobulbar palsy. Rev Neurol (Paris). 2009; 165(1):86-88. French.

41. Chu CI, Po H. Pathological laughing with syncope and occipital hypoperfusion as an unusual late effect of pontine infarct. Neurol Asia. 2010;15(2):179-183.

42. Dabby R, Watemberg N, Lampl Y, Eilam A, Rapaport A, Sadeh M. Pathological laughter as a symptom of midbrain infarction. Behav Neurol. 2004;15(3-4):73-76.

43. Elyas AE, Bulters DO, Sparrow OC. Pathological laughter and crying in patients with pontine lesions. J Neurosurg Pediatr. 2011;8(6):544-547.

44. Elyas A, Bulters D, Sparrow O. Pathological laughter and crying in pontine lesions: A case report and analysis of lesions in the literature. Childs Nerv Syst. 2010;26(4 Suppl 1):587. Abstract. 
45. Hackett M, Yang M, Anderson C, Horrocks J, House A. Emotionalism after stroke: What is it, is it a problem and what can we do about it? Int J Stroke. 2010;5:13.

46. Kasikci S, Bek H, Akgun M, et al. A case of pathological laughing and crying caused by posterior circulation embolism after embolisation of nasopharyngeal angiofibroma. Abstracts of the Twenty-First Meeting of the European Neurological Society; May 28-31, 2011; Lisbon, Portugal. J Neurol. 2011;258(Suppl 1):S3-S295.

47. Kim SW, Shin IS, Kim JM, Lim SY, Yang SY, Yoon JS. Mirtazapine treatment for pathological laughing and crying after stroke. Clin Neuropharmacol. 2005;28(5):249-251.

48. Lee S, Kim DY, Kim JS, et al. When should brain imaging be performed? A case report of caudate nucleus infarct. Psychiatry (Edgmont). 2010;7(1):31-33.

49. Lobjanidze N, Janelidze M, Shakarishvili R, Beridze M, Kvirkvelia N. Neuroradiological pecularities of neuropsychiatric complications after stroke. Clin EEG Neurosci. 2009;40(3):217.

50. Møller M, Andersen G, Gjedde A. Serotonin 5HT1A receptor availability and pathological crying after stroke. Acta Neurol Scand. 2007;116(2):83-90.

51. Oh K, Kim HJ, Kim BJ, Park KW, Lee DH. Pathological laughter as an unusual manifestation of acute stroke. Eur Neurol. 2008;59(1-2):83-84.

52. Smith E, Delargy M. Locked-in syndrome. BMJ. 2005;330(7488): 406-409.

53. Tuncer N, Afsar N, Tanridag T, Us O. Pathological laughing following pontine infarction due to basilar artery stenosis. Marmara Med J. 2005; 18(1):28-31.

54. Uzunca I, Utku U, Asil T, Celik Y. "Fou rire prodromique" associated with simultaneous bilateral capsular genu infarction. J Clin Neurosci. 2005;12(2):174-175.

55. Arciniegas DB. New-onset bipolar disorder in late life: a case of mistaken identity. Am J Psychiatry. 2006;163(2):198-203.

56. Chai SB, Naik SR, Sim K. MELAS associated pathological hyperemotionalism: a case report. Ann Acad Med Singapore. 2011; 40(9):418-419.

57. Filley CM. White matter: beyond focal disconnection. Neurol Clin. 2011;29(1):81-97.

58. Iwasaki Y. Three cases of Creutzfeldt-Jakob disease with prion protein gene codon 180 mutation presenting with pathological laughing and crying. J Neurol Sci. 2012;319(1-2):47-50.

59. Liberski PP, Brown P. Kuru-fifty years later. Neurol Neurochir Pol. 2007;41(6):548-556.

60. Mendez MF, Lauterbach EC, Sampson SM; for ANPA Committee on Research. An evidence-based review of the psychopathology of frontotemporal dementia: a report of the ANPA Committee on Research. J Neuropsychiatry Clin Neurosci. 2008; 20(2):130-149.

61. Mimica N, Drmić S, Presecki P. Involuntary emotional expression disorder in Alzheimer's disease - psychopharmacotherapy aspects Psychiatr Danub. 2009;21(3):425-428.

62. Thümler BH, Urban PP, Davids E, et al. Dysarthria and pathological laughter/crying as presenting symptoms of corticobasal-ganglionic degeneration syndrome. J Neurol. 2003;250(9):1107-1108.

63. Allman P. Drug treatment of emotionalism following brain damage. J R Soc Med. 1992;85(7):423-424.

64. Chahine LM, Chemali Z. Du rire aux larmes: pathological laughing and crying in patients with traumatic brain injury and treatment with lamotrigine. Epilepsy Behav. 2006;8(3):610-615.

65. Fisher T, Shamay-Tsoory SG, Eran A, Aharon-Peretz J. Characterization of recovery and neuropsychological consequences of orbitofrontal lesion: a case study. Neurocase. 2011;17(3):285-293.

66. Tateno A, Jorge RE, Robinson RG. Pathological laughing and crying following traumatic brain injury. J Neuropsychiatry Clin Neurosci. 2004;16(4):426-434

67. Bhaskar IP, Chacko AG, Daniel RT. Brainstem compression from a trigeminal schwannoma presenting with pathological crying. J Clin Neurosci. 2008;15(3):322-324.
68. Büyükgebiz A. Hypothalamic hamartoma, gelastic epilepsy and precocious puberty. J Pediatr Endocrinol Metab. 2007;20(3):377.

69. Cao Z, Ly J, Ding Z, Du H. Pathological laughter in a patient with Rathke cleft cyst. J Clin Neurosci. 2008;15(11):1279-1282.

70. Cheng TJ, Ke DS, Tsai TC. Petroclival meningioma presenting with pathological laughter: report of a case and review of the literature. Acta Neurologica Taiwanica. 2003;12(4):187-190.

71. Famularo G, Corsi FM, Minisola G, De Simone C, Nicotra GC. Cerebellar tumour presenting with pathological laughter and gelastic syncope. Eur J Neurol. 2007;14(8):940-943.

72. Goel A, Muzumdar D. Trigeminal neurinomas. Neurosurg Q. 2003; 13(3):162-178.

73. Hargrave DR, Mabbott DJ, Bouffet E. Pathological laughter and behavioural change in childhood pontine glioma. J Neurooncol. 2006; 77(3):267-271.

74. Jagetia A, Pratap Kumar N, Singh D, Sinha S. Pathological laughter in trigeminal schwannoma: case report and review of the literature. Neurosurg Rev. 2006;29(4):348-352.

75. Machado AG, Aguiar PH, Marino R Jr. Pathological laughter in a patient with trigeminal neurinoma. Arq Neuropsiquiatr. 2002;60(4): 1000-1002.

76. Maheshwari S, Figueiredo A, Goel A. Pathological crying as a manifestation of spontaneous haemorrhage in a pontine cavernous haemangioma. J Clin Neurosci. 2010;17(5):662-663.

77. Muzumdar DP, Goel A. Pathological laughter as a presenting symptom of acoustic schwannoma: report of two cases. J Clin Neurosci. 2003; 10(3):384-386.

78. Parvizi J, Schiffer R. Exaggerated crying and tremor with a cerebellar cyst. J Neuropsychiatry Clin Neurosci. 2007;19(2):187-190.

79. Siddiqui MA, Rizvi SA, Ahmad I, Ahmad K, Ullah E, Akhtar J. Isolated pontine tuberculoma presenting as "fou rire prodromique". JNeurosurg Pediatr. 2012;10(3):189-191.

80. Striano S, Santulli L, Ianniciello M, Ferretti M, Romanelli P, Striano P. The gelastic seizures-hypothalamic hamartoma syndrome: facts, hypotheses, and perspectives. Epilepsy Behav. 2012; 24(1):7-13.

81. Tsutsumi S, Yasumoto Y, Ito M. Pathological laughter caused by frontal glioblastoma - Case report. Neurol Med Chir (Tokyo). 2008;48(7): 307-310.

82. Battaglia A, Fisch GS. Introduction: behavioral phenotypes in neurogenetic syndromes. Am J Med Genet C Semin Med Genet. 2010; 154C(4):387-388.

83. Beck D, Black D. Possible etiologic mechanism of pathological laughter: case report. Ann Clin Psychiatry. 1990;2(4):255-257.

84. Cetlin RS, Rodrigues GR, Pena-Pereira MA, Oliveira DS, Souza CP, Tumas V. Teaching video neuroimages: excessive grinning in Wilson disease. Neurology. 2009;73(14):e73.

85. Dimova P, Boneva I, Todorova A, Minotti L, Kahane P. Gelastic seizures in ring chromosome 20 syndrome: a case report with video illustration. Epileptic Disord. 2012;14(2):181-186.

86. Dopper EG, Seelaar H, Chiu WZ, et al. Symmetrical corticobasal syndrome caused by a novel C.314dup progranulin mutation. $J \mathrm{Mol}$ Neurosci. 2011;45(3):354-358.

87. Gitiaux C, Ceballos-Picot I, Marie S, et al. Misleading behavioural phenotype with adenylosuccinate lyase deficiency. Eur J Hum Genet. 2009;17(1):133-136.

88. Guimarães J, Bugalho P, Coutinho P. Pathological crying in patients with Machado-Joseph disease. Mov Disord. 2008;23(3):470-471.

89. Grosso S, Anichini C, Pucci L, Vivarelli R, Pianigiani R, Balestri P. Severe mental retardation, absent speech, ataxia, seizures, subtle facial dysmorphisms, and paroxysmal laughter. Ital J Pediatr. 2006;32(5):276-279.

90. Horsler K, Oliver C. The behavioural phenotype of Angelman syndrome. J Intellect Disabil Res. 2006;50(Pt 1):33-53.

91. Jay V, Becker LE, Chan FW, Perry TL Sr. Puppet-like syndrome of Angelman: a pathologic and neurochemical study. Neurology. 1991; 41(3):416-422. 
92. Petchrutchatachart S, Limotai N, Jagota P, Singmaneesakulchai S, Bhidayasiri R. Case report: Neuroferritinopathy with early bulbar involvement. Parkinsonism Relat Disord. 2012;18:S65.

93. Sarkar PA, Shigli A, Patidar C. Happy puppet syndrome. BMJ Case Rep. 2011;2011.

94. Scheiffele P, Beg AA. Neuroscience: Angelman syndrome connections. Nature. 2010;468(7326):907-908.

95. Dimova PS, Bojinova VS, Milanov IG. Transient mutism and pathologic laughter in the course of cerebellitis. Pediatr Neurol. 2009; 41(1):49-52.

96. Zullino D, Lyon I, Morena P, Baumann P. Pathologic laughter associated with paroxetine treatment. J Clin Psychopharmacol. 2002; 22(2):231.

97. Barbanti P, Fabbrini G, Berardelli A. Acute pathological laughter induced by sumatriptan. Cephalalgia. 2008;28(1):92-93.

98. Low HL, Sayer FT, Honey CR. Pathological crying caused by highfrequency stimulation in the region of the caudal internal capsule. Arch Neurol. 2008;65(2):264-266.

99. Okun MS, Raju DV, Walter BL, et al. Pseudobulbar crying induced by stimulation in the region of the subthalamic nucleus. $J$ Neurol Neurosurg Psychiatry. 2004;75(6):921-923.

100. Sudhyadhom A, Bova FJ, Foote KD, Rosado CA, Kirsch-Darrow L, Okun MS. Limbic, associative, and motor territories within the targets for deep brain stimulation: potential clinical implication. Curr Neurol Neurosci Rep. 2007;7(4):278-289.

101. Wojtecki L, Nickel J, Timmermann L, et al. Pathological crying induced by deep brain stimulation. Mov Disord. 2007;22(9):1314-1316.

102. Wojtecki L, Timmermann L, Groiss SJ, et al. Long-term time course of affective lability after subthalamic deep brain stimulation electrode implantation. Neurocase. 2011;17(6):527-532.

103. Sartori E, Belliard S, Chevrier C, Trebon P, Chaperon J, Edan G. From psychometry to neuropsychological disability in multiple sclerosis: a new brief French cognitive screening battery and cognitive risk factors. Rev Neurol (Paris). 2006;162(5):603-615. French.

104. Dark FL, McGrath JJ, Ron MA. Pathological laughing and crying. Aust N Z J Psychiatry. 1996;30(4):472-479.

105. Colamonico J, Formella A, Bradley W. Pseudobulbar affect: burden of illness in the USA. Adv Ther. 2012;29(9):775-798.

106. Oliver D, Campbell C, Wright A. Palliative care of patients with motor neurone disease. Prog Palliat Care. 2007;15(6):285-293.

107. Rabins PV, Arciniegas DB. Pathophysiology of involuntary emotional expression disorder. CNS Spectr. 2007;12(4 Supp1 5):17-22.

108. Parvizi J, Anderson SW, Martin CO, Damasio H, Damasio AR. Pathological laughter and crying: a link to the cerebellum. Brain. 2001;124(Pt 9):1708-1719.

109. Schmahmann JD, Weilburg JB, Sherman JC. The neuropsychiatry of the cerebellum - insights from the clinic. Cerebellum. 2007;6(3): 254-267.

110. Richter RW. The pathophysiology of emotional lability: many paths to a common destination. Am J Geriatr Pharmacother. 2005; 3(Suppl A):9-11.

111. Wild B, Rodden FA, Grodd W, Ruch W. Neural correlates of laughter and humour. Brain. 2003;126(10):2121-2138.

112. Pearce JM. Some neurological aspects of laughter. Eur Neurol. 2004;52(3):169-171.

113. Kosaka H, Omata N, Omori M, et al. Abnormal pontine activation in pathological laughing as shown by functional magnetic resonance imaging. J Neurol Neurosurg Psychiatry. 2006;77(12): 1376-1380.

114. Hesse S, Barthel H, Schwarz J, Sabri O, Müller U. Advances in in vivo imaging of serotonergic neurons in neuropsychiatric disorders. Neurosci Biobehav Rev. 2004;28(6):547-563.

115. Wilson SA. Pathological Laughing and Crying. Proc R Soc Med. 1923;16(Sect Psych):39-40.

116. Coelho M, Ferro JM. Fou rire prodromique. Case report and systematic review of the literature. Cerebrovasc Dis. 2003;16(1): 101-104.
117. Boylan LS, Kaley TJ, Singh A, Devinsky O. Postictal laughter following absence status epilepticus. Epilepsy Behav. 2003;4(6):773-775.

118. Chai Y, Adamolekun B. Cryptogenic gelastic epilepsy originating from the right temporal lobe. Med Princ Pract. 2010;19(2):153-158.

119. Kovac S, Deppe M, Mohammadi S, et al. Gelastic seizures: a case of lateral frontal lobe epilepsy and review of the literature. Epilepsy Behav. 2009;15(2):249-253.

120. Montalto M, Impastato M, Lo Bue A, Sorrentino A, Barbagallo A, Mangano S. Gelastic seizures: Clinical and video-EEG analysis of a paediatric case with a frontal focus. Bollettino - Lega Italiana Contro l'Epilessia. 2006;133:171-172.

121. NgYT. Correct definition and reference of the term "status gelasticus". J Child Neurol. 2008;23(9):1088.

122. Pearce JM. A note on gelastic epilepsy. Eur Neurol. 2004;52(3): 172-174.

123. Murai T, Barthel H, Berrouschot J, Sorger D, von Cramon DY, Müller U. Neuroimaging of serotonin transporters in post-stroke pathological crying. Psychiatry Res. 2003;123(3):207-211.

124. Umeoka S, Baba K, Mihara T. Symptomatic laughter in a patient with orbitofrontal seizure: a surgical case with intracranial electroencephalographic study: case report. Neurosurgery. 2008;63(6):E1205-E1206.

125. Arciniegas DB. A clinical overview of pseudobulbar affect. Am J Geriatr Pharmacother. 2005;3(Suppl A):4-8.

126. Ginsberg DL, Anderson KE, Chow TW, et al. The differential diagnosis of pseudobulbar affect (PBA). Distinguishing PBA among disorders of mood and affect. CNS Spectr. 2005;10(5):1-15.

127. Parvizi J, Arciniegas DB, Bernardini GL, et al. Diagnosis and management of pathological laughter and crying. Mayo Clin Proc. 2006;81(11):1482-1486.

128. Smith RA, Berg JE, Pope LE, Callahan JD, Wynn D, Thisted RA. Validation of the CNS emotional lability scale for pseudobulbar affect (pathological laughing and crying) in multiple sclerosis patients. Mult Scler. 2004;10(6):679-685.

129. Robinson RG, Parikh RM, Lipsey JR, Starkstein SE, Price TR. Pathological laughing and crying following stroke: validation of a measurement scale and a double-blind treatment study. Am J Psychiatry. 1993;150(2):286-293.

130. Starkstein SE, Migliorelli R, Tesón A, et al. Prevalence and clinical correlates of pathological affective displaying Alzheimer's disease. $J$ Neurol Neurosurg Psychiatry. 1995;59(1):55-60.

131. Newsom-Davis IC, Abrahams S, Goldstein LH, Leigh PN. The emotional lability questionnaire: a new measure of emotional lability in amyotrophic lateral sclerosis. J Neurol Sci. 1999;169(1-2):22-25.

132. Palmieri A, Abrahams S, Sorarù G, et al. Emotional lability in MND: relationship to cognition and psychopathology and impact on caregivers. J Neurol Sci. 2009;278(1-2):16-20.

133. Anonymous. Pathological laughing and crying may be caused by many neurological disorders and is highly responsive to treatment. Drugs and Therapy Perspectives. 2009;25(4):18-20.

134. Brooks BR. Involuntary emotional expression disorder: treating the untreated. CNS Spectr. 2007;12(4 Suppl 5):23-27.

135. Pioro EP. Current concepts in the pharmacotherapy of pseudobulbar affect. Drugs. 2011;71(9):1193-1207.

136. Weintraub D. Therapeutic options for emotional lability: current and emerging treatments. Am J Geriatr Pharmacother. 2005;3(Suppl 1): $12-15$.

137. Wortzel HS, Anderson CA, Arciniegas DB. Treatment of pathologic laughing and crying. Curr Treat Options Neurol. 2007;9(5): 371-380.

138. Hackett ML, Yang M, Anderson CS, Horrocks JA, House AO. Using antidepressants to treat emotionalism after stroke. Cerebrovasc Dis. Conference: May 2010;29:288.

139. Andersen G, Stylsvig M, Sunde N. Citalopram treatment of traumatic brain damage in a 6-year-old boy. J Neurotrauma. 1999;16(4): 341-344.

140. Andersen G, Vestergaard K, Riis JO. Citalopram for post-stroke pathological crying. Lancet. 1993;342(8875):837-839. 
141. Kaschka WP, Meyer A, Schier KR, Fröscher W. Treatment of pathological crying with citalopram. Pharmacopsychiatry. 2001;34(6): 254-258.

142. King RR, Reiss JP. Treatment of pseudobulbar affect with citalopram in a patient with progressive multifocal leukoencephalopthy. J Clin Neurosci. 2012;19(1):185-186.

143. Burns A, Russell E, Stratton-Powell H, Tyrell P, O’Neill P, Baldwin R. Sertraline in stroke-associated lability of mood. Int $J$ Geriatr Psychiatry. 1999;14(8):681-685.

144. Mukand J, Kaplan M, Senno RG, Bishop DS. Pathological crying and laughing: treatment with sertraline. Arch Phys Med Rehabil. 1996;77(12):1309-1311.

145. Okun MS, Heilman KM, Vitek JL. Treatment of pseudobulbar laughter after gamma knife thalamotomy. Mov Disord. 2002;17(3):622-624.

146. Lauterbach EC, Schweri MM. Amelioration of pseudobulbar affect by fluoxetine: possible alteration of dopamine-related pathophysiology by a selective serotonin reuptake inhibitor. J Clin Psychopharmacol. 1991;11(6):392-393.

147. Seliger GM, Hornstein A, Flax J, Herbert J, Schroeder K. Fluoxetine improves emotional incontinence. Brain Inj. 1992;6(3):267-270.

148. Sloan RL, Brown KW, Pentland B. Fluoxetine as a treatment for emotional lability after brain injury. Brain Inj. 1992;6(4):315-319.

149. Tsai WC, Lai JS, Wang TG. Treatment of emotionalism with fluoxetine during rehabilitation. Scand J Rehabil Med. 1998;30(3):145-149.

150. Müller U, Murai T, Bauer-Wittmund T, von Cramon DY. Paroxetine versus citalopram treatment of pathological crying after brain injury. Brain Inj. 1999;13(10):805-811.

151. Iannaccone $S$, Ferini-Strambi L. Pharmacologic treatment of emotional lability. Clin Neuropharmacol. 1996;19(6):532-535.

152. Schiffer RB, Herndon RM, Rudick RA. Treatment of pathologic laughing and weeping with amitriptyline. NEngl J Med. 1985;312(23): 1480-1482.

153. Lawson IR, MacLeod RD. The use of imipramine ("Tofranil") and other psychotropic drugs in organic emotionalism. Br J Psychiatry. 1969;115(520):281-285.

154. Smith AG, Montealegre-Orjuela M, Douglas JE, Jenkins EA. Venlafaxine for pathological crying after stroke. J Clin Psychiatry. 2003;64(6):731-732.

155. Ferentinos P, Paparrigopoulos T, Rentzos M, Evdokimidis I. Duloxetine for pathological laughing and crying. Int J Neuropsychopharmacol. 2009;12(10):1429-1430.

156. Møller M, Andersen G. Inhibition of selective noradrenergic reuptake as treatment of pathological laughter. J Clin Psychopharmacol. 2007; 27(1):108-110

157. Ginsberg DL. Lamotrigine Treatment of Poststroke Pathological Laughing and Crying. Prim Psychiatry. 2004;11(3):17-18.

158. Ramasubbu R. Lamotrigine treatment for post-stroke pathological laughing and crying. Clin Neuropharmacol. 2003;26(5):233-235.

159. Chen YR, Huang YP, Lin SJ, Kuan TH, Lin CH. Effectiveness of quetiapine for poststroke pathological laughing: case report and review of the literature. Clin Neuropharmacol. 2010;33(6):319-322.
160. Magaudda A, Imbesi D, Di Rosa G. Efficacy of aripiprazole in a child with involuntary emotional expression disorder. J Neuropsychiatry Clin Neurosci. 2012;24(2):E5-E6.

161. Udaka F, Yamao S, Nagata H, Nakamura S, Kameyama M. Pathologic laughing and crying treated with levodopa. Arch Neurol. 1984;41(10): 1095-1096.

162. Wolf JK, Santana HB, Thorpy M. Treatment of "emotional incontinence" with levodopa. Neurology. 1979;29(10):1435-1436.

163. Pioro EP, Brooks BR, Cummings J, et al. Dextromethorphan plus ultra low-dose quinidine reduces pseudobulbar affect. Ann Neurol. 2010 68(5):693-702

164. Brooks BR, Cummings J, Pioro EP, Schiffer R, Wynn D, Hepner A. Star trial: Sub-analysis of an international, multi-center, placebo-controlled study of AVP-923 (dextromethorphan/quinidine) for the treatment of pseudobulbar affect (PBA) in amyotrophic lateral sclerosis (ALS) patients. Amyotroph Lateral Scler. 2009;10:29.

165. Panitch HS, Thisted RA, Smith RA, et al; for Psuedobulbar Affect in Multiple Sclerosis Study Group. Randomized, controlled trial of dextromethorphan/quinidine for pseudobulbar affect in multiple sclerosis. Ann Neurol. 2006;59(5):780-787.

166. Garnock-Jones KP. Dextromethorphan/quinidine: in pseudobulbar affect. CNS Drugs. 2011;25(5):435-445.

167. Rosen H. Dextromethorphan/quinidine sulfate for pseudobulbar affect. Drugs Today (Barc). 2008;44(9):661-668.

168. Werling LL, Keller A, Frank JG, Nuwayhid SJ. A comparison of the binding profiles of dextromethorphan, memantine, fluoxetine and amitriptyline: treatment of involuntary emotional expression disorder. Exp Neurol. 2007;207(2):248-257.

169. Giacobbe P, Flint A. Pharmacological treatment of post-stroke pathological laughing and crying. J Psychiatry Neurosci. 2007; 32(5):384.

170. Andersen G, Larsson H, Horsdal HT, Johnsen SP. Selective serotonin reuptake inhibitors and clinical outcome among patients with ischemic stroke: A nationwide propensity-score matched follow-up study. Int $J$ Stroke. 2010;5(Suppl 2):207.

171. Sacco S, Sarà M, Pistoia F, Conson M, Albertini G, Carolei A Management of pathologic laughter and crying in patients with locked-in syndrome: a report of 4 Cases. Arch Phys Med Rehabil. 2008;89(4):775-778.

172. Kasprisin A. Alternative cognitive therapy for emotional instability (pathologic laughing and crying). Phys Med Rehabil Clin NAm. 2004; 15(4):883-917.

173. Yun SP, Jung WS, Park SU, et al. Hwangryunhaedogtang (huanglianjiedutang) treatment for pathological laughter after stroke and importance of patterns identification: a preliminary study. Am J Chin Med. 2007;35(5):725-733.
Degenerative Neurological and Neuromuscular Disease

\section{Publish your work in this journal}

Degenerative Neurological and Neuromuscular Disease is an international, peer-reviewed, open access journal focusing on research into degenerative neurological and neuromuscular disease, identification of therapeutic targets and the optimal use of preventative and integrated treatment interventions to achieve improved outcomes, enhanced

\section{Dovepress}

survival and quality of life for the patient. The manuscript management system is completely online and includes a very quick and fair peer-review system. Visit http://www.dovepress.com/testimonials.php to read real quotes from published authors. 